\title{
EXAMINATION OF VANADIUM EFFECT ON GENERAL MECHANICAL CHARACTERISTICS OF Bi-2223 MATERIALS VIA SEMI-EMPIRIC MODELS
}

\author{
Ugur SOYKAN 1,*id , Fidan VELIYEVA ${ }^{2}$ (i) , Gurcan YILDIRIM ${ }^{3}$ \\ ${ }^{1}$ Yenicaga Yasar Celik Vocational High School, Bolu Abant Izzet Baysal University, Bolu-Turkey, 14300 \\ ${ }^{2}$ Department of Chemistry, Bolu Abant Izzet Baysal University, Bolu-Turkey, 14000 \\ ${ }^{3}$ Bolu Abant Izzet Baysal University, Department of Mechanical Engineering, Bolu-Turkey, 14280
}

\begin{abstract}
In the current work, we semi-empirically investigate the load-independent Vickers hardness values of vanadium added Bi2223 compounds in the plateau limit regions evaluated from the experimental microhardness graphics (Vickers hardness parameters versus applied indentation test loads) to determine the role of vanadium particles on the general mechanical characteristics with the aid of six mechanical modeling approaches, namely law of Meyer, proportional sample resistance, elastic/plastic deformation, modified proportional sample resistance, Hays-Kendall and indentation-induced cracking models. Throughout the study, the samples are prepared with the different molar rations varying from $\mathrm{x}=0$ to 0.3 by the conventional ceramic method in the normal atmospheric pressure at the room temperature conditions. All the model findings show that the mechanical performances tend to constantly reduce with increasing the vanadium concentration level embedded in the Bi-2223 superconducting crystal system. This is in accordance to the fact that the concentration level of vanadium remarkably damages the main structural problems and permanent irreversible deformations. In this respect, it is not wrong to verify that the vanadium inclusions unstabilize the inherit durable tetragonal phase of Bi-2223 inorganic solids, resulting in the regression in the mechanical durability (resistance towards to the applied loads) in case of the applied test loads. Moreover, the models indicate that every material prepared exhibits the conventional indentation size effect (related to the formation of elastic and plastic deformations in the host crystal structures simultaneously due to the recovery of systems) but within the suppression trend. Shortly, all the semi-empiric models preferred in the present work are found to be useful descriptors to define the suitable relationship between the ion-addition mechanism in the crystal lattice and mechanical durability/performances of vanadium-added Bi-2223 materials. We should, of course, declare here that Hays-Kendall approach is gathered to be the best approach model for the load-independent Vickers hardness values in the plateau limit regions.
\end{abstract}

Keywords: Vanadium-added Bi-2223 material, Semi-empiric models; Mechanical durability, Plateau limit regions

\section{INTRODUCTION}

Superconductivity phenomenon is defined as the state of zero electrical resistivity and perfect diamagnetism (expelling the magnetic flux from the material). No other physical phenomenon likes the superconductivity characteristic behavior; or in the literature there has been no strong clue on the relatable to the atomic number, atomic weight, ionization potential, angular momentum, electron affinity, electro-negativity, work function, electron binding energy or the related compounds such as the metals, halogens, metalloids, non-superconducting materials, noble gases, chalcogens, alloys, nonmetals, organic compounds, inorganic materials and dielectric materials [1]. Hence, it is just based on the last descriptors that the superconductivity phenomenon correlates scarcely with the characteristic properties such as normal resistivity, conductivity, physical and mechanical features. Accordingly, the phenomenon of superconductivity can be found in all the kinds of materials. In fact, non-superconducting compounds drive the superconductivity at even lower temperature (below the critical transition temperature values).

At the same time, the second term of perfect diamagnetism has directly attracted great attention of the scientists for the usages of metallurgical and materials science engineering, power transmission, magnetic separation, motors, transformers, refrigeration, electro-optic, generators, particle

*Corresponding Author: ugursoykan@ibu.edu.tr

Received: 30.10.2020 Published: 27.11.2020 
accelerators, spintronics, innovative energy infrastructure sectors, future hydrogen society, medicine areas, levitated trains, imaging technology, sensitive process control, electric power cable, magnetic energy storage, heavy-industrial technology and large-scale areas application fields [2-8]. As well known that according to the magnetic carrying characteristics, the superconducting materials are differentiated into two types: Type-I and Type-II. Among the materials, the superconductivity driven in the Type-II cuprate materials is hardly any affected at even higher magnetic field applicated. In fact, the latter superconducting compounds obtain much superior characteristics such as relatively smaller energy power consumptions due to the presence of losses or heat dissipations in the crystal structures, extremely larger operating temperature, extensively higher pinning ability/capacity (satisfactory size of critical fields), tremendously greater current and external magnetic field carrying capacity as compared to those of the former superconductors [9-12]. Besides, the other promising features regarding as optical and electronic behaviors are clearly mentioned in the same publications of [9-12]. Moreover, largely lower material-preparation procedures including the chemical costs, simple availability of starting powders, light weight/size, harmless chemical contents and easy phase formation as well as the environmental benefits can be listed as the advantages of Type-II cuprate ceramic materials in comparison with the Type-I superconducting materials. All the appealing features provided above enable the Type-II superconducting materials to use in the magnetic energy storage, innovative energy infrastructure, medical diagnosis, heavy-industrial technology, sensitive process control, hydrogen society, spintronics, future refrigeration and large-scale areas application fields [212]. All in all, the scientists have extensively studied especially on the Type-II cuprate materials. It is to be mentioned here that the Bi-2223 superconducting cuprate ceramics (from the parents of Type-II cuprate ceramic materials) exhibit extensively higher critical current densities and critical transition temperatures among the Type-II cuprate superconducting materials [13-17].

In the current work, we try to determine experimentally and theoretically the vital role of vanadium addition in the host Bi-2223 cuprate ceramic materials on the original or true (load-independent) microhardness parameters by means of the available theoretical models as regards law of Meyer $(M L)$, proportional sample resistance $(P S R)$, elastic/plastic deformation $(E P)$, modified proportional sample resistance $(M P S R)$, Hays-Kendall $(H K)$ and indentation-induced cracking (ICR) models approaches founded on the Vickers hardness experimental tests to be conducted at the different applied indentation loads in a range of $0.245 \mathrm{~N}-2.940$. However, among them only three approaches $(M L$, $M P S R$ and $H K$ ) exhibit the most accurate results in comparison with the experimental findings. Thus, in this paper we give only the results of these three models.

\section{EXPERIMENTAL PROCEDURES FOR VANADIUM ADDED CERAMIC CUPRATE MATERIALS}

In the current work, we prepare the bulk vanadium added cuprate-layered perovskite superconducting materials in the different molar ratio in a range of $0 \leq x \leq 0.10$ with the aid of conventional solid-state reaction method in the medium of air. The crucial variations in the load-independent microhardness parameters with the vanadium addition in the Bi-2223 superconducting crystal structure are analyzed by using the available theoretical models such as the Meyer's law $(M L)$, modified proportional sample resistance model (MPSR) and Hays-Kendall $(H K)$ approaches based on the Vickers hardness experimental tests exerted at the various external indentation loads between $0.245 \mathrm{~N}$ and $2.940 \mathrm{~N}$ for the first time in this study. In this regard, we firstly purchase the powder of chemicals such as $\mathrm{Bi}_{2} \mathrm{O}_{3}$, $\mathrm{SrCO}_{3}, \mathrm{CuO}, \mathrm{CaCO}_{3}$ and $\mathrm{TiO}_{2}$ materials within the high purity of about $\% 99.99$ or higher from Alfa Aesar exclusive distributor in Ankara. Then, we weigh all the chemicals in terms of the stoichiometric ratios by means of an electronic balance (within four digits) and put the chemicals in a tube so that the ball milling process can be started immediately. Here, the process is done for 6-hour duration in the atmospheric pressure conditions for the homogeneous mixture of chemicals. After the ball milling process, the homogeneous mixture of powders is exposed to the manual grinding process in an agate mortar by using a grinder for the duration of $30 \mathrm{~min}$ to minimize the chemicals into the desired particle sizes. The homogeneous mixture of powders is calcined at the temperature of $800{ }^{\circ} \mathrm{C}$ for 36 -hour duration 
in porcelain crucibles in the air atmosphere. During the calcination process, the heating and cooling rates are adjusted as $5{ }^{\circ} \mathrm{C}$ per min. The calcined mixture (in the formation of the blackish color) is removed from the furnace and is again ground by the grinder in the agate mortar for about the duration of 30 min. Right after, we press the mixture of powder into the rectangular bars with the size of $1.5 \times 0.5 \times 0.2 \mathrm{~cm}^{3}$ by using $300 \mathrm{MPa}$ press load at the normal atmospheric pressure conditions. The main-heat treatments of the solid bars are performed at the annealing temperature of $850{ }^{\circ} \mathrm{C}$ for 24 hour duration. The solid bars prepared in this work will thenceforward be presented as the pure, V-1, $\mathrm{V}-2, \mathrm{~V}-3, \mathrm{~V}-4, \mathrm{~V}-5$ and V-6 according to the molar ratios of $\mathrm{x}=0.00,0.01,0.03,0.05,0.07,0.10$ and 0.30 , respectively. The experimental measurements are performed using the model digital microhardness tester of SHIMADZU HVM-2 in the different external test loads of $0.245 \mathrm{~N}-2.940 \mathrm{~N}$ for 10 seconds at the normal atmospheric pressure conditions. The critical changes in the original microhardness performance parameters of $\mathrm{Bi}-2223$ superconducting materials with the vanadium addition in the crystal structure are surveyed by the way of the available theoretical models provided above.

\section{RESULTS AND DISCUSSION}

To examine the vital variations based on the vanadium addition in the crystal structure of loadindependent microhardness performance parameters belonging to the bulk poly-crystallized Bi-2223 superconducting ceramic compounds, we gather the Vickers microhardness $(\mathrm{Hv})$ parameters at the various applied indentation test loads in the range of $0.245 \mathrm{~N}-2.940 \mathrm{~N}$ and tabulate every $\mathrm{Hv}$ value for the materials in Table 1.

Table 1 Reasonable mean diagonal lengths and Vickers hardness parameters at various applied indentation test loads of $0.245 \mathrm{~N}-2.940 \mathrm{~N}$ for bulk vanadium added $\mathrm{Bi}-2223$ superconducting materials $(0 \leq \mathrm{x} \leq 0.30)$.

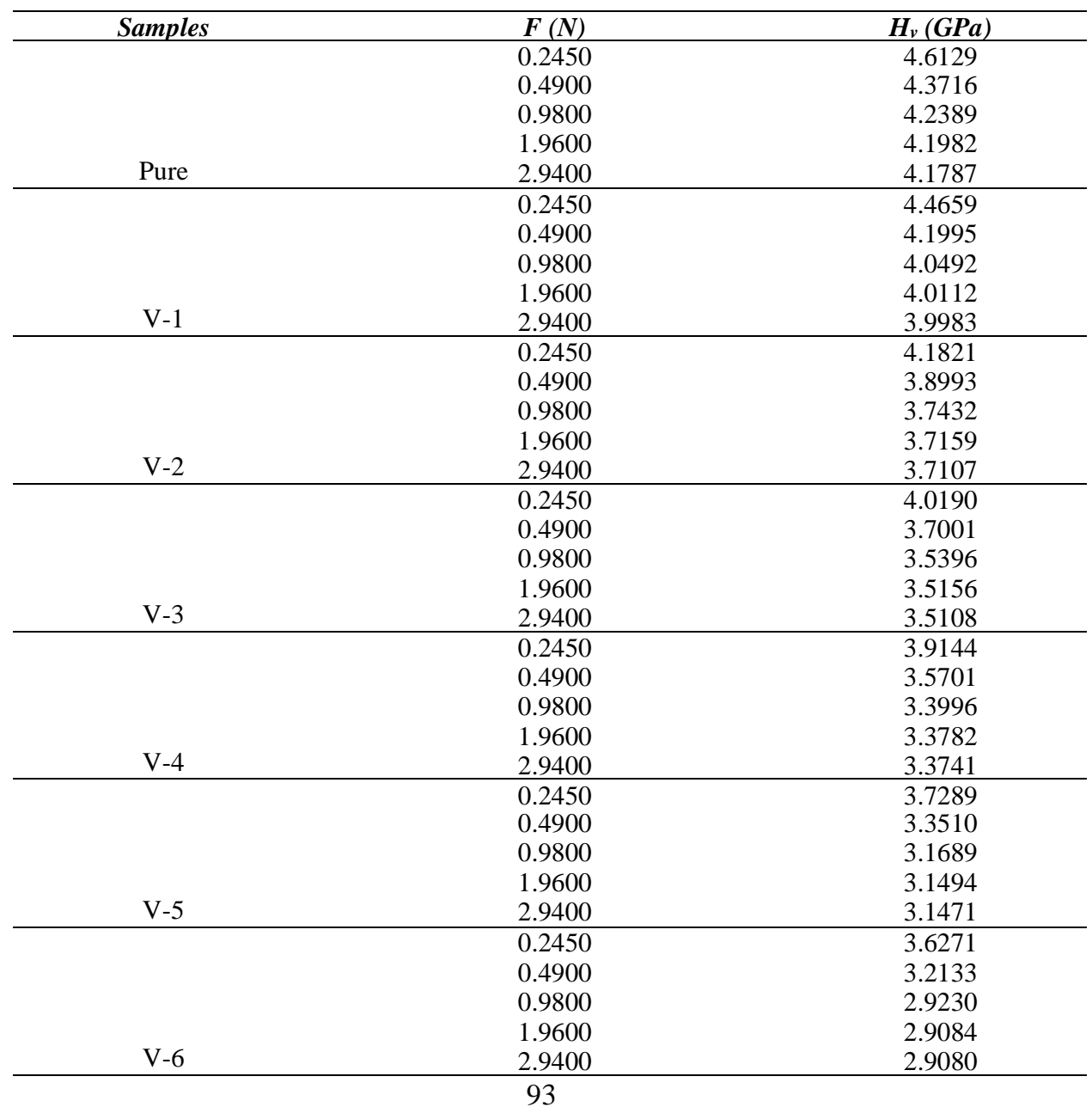




\subsection{Load-Dependent Vickers Performance Parameters of Solid Vanadium Added Bi-2223 Materials with Regard to Meyer's Law}

The theoreticians prefer the Meyer's law to determine the differentiation in the load-independent mechanical performances of the superconducting ceramic compounds with any changes in the preparation conditions (doping, addition, partial substitution, operational procedure and the heattreatment environments including the pressure, time, temperature, calcination and sintering ambient atmosphere), dopant type, dopant quantity, transition metal evaporation and chemical composition [18, 19]. That the model provides the reliable, valid and useful results for the superconducting material exhibiting both the typical indentation size effect (ISE) and reverse indentation size effect (RISE) behaviors is another advantage of the model. In the Meyer's law there is a strong and sensitive link between the external test loads and exponential power of $n$ related to the mean diagonal length. One can see the relation below [20]:

$$
F=A_{\text {Meyer }} d^{n}
$$

in the relation, $A_{\text {Meyer }}$ is in associated with the typical Vickers hardness parameters for the materials studied when the abbreviation of $n$ is in correspondence to the Meyer number for any applied indentation test loads. Besides, one can anticipate the mechanical characteristic behavior of a sample with regard to the Meyer's law. Namely, in case of $\mathrm{n}<2$ ( $n$ is lesser than 2), the sample exhibits the typical ISE behavior. As for the state of $n>2$ (the exponential power value of $n$ is higher than 2), the material studied presents the unusual RISE nature. At the last condition of $n=2$ ( $\mathrm{n}$ is equal to 2 ), the material is called as Kick's material whose mechanical characteristic behavior is totally independent upon the indentation test load applied $[21,22]$. As for the investigation according to the Meyer's law of our materials in Figure 1 (linear differentiations of $\ln F$ over $\ln d$ curves), all the exponential power values of $n$ are found to be lesser than 2 (Table 2). This is attributed to the fact that every material (pure and vanadium added Bi-2223 superconducting materials) presents the typical ISE feature but in the reduction trend with the enhancement in the vanadium addition level [23]. Numerically, the $n$ value is found to decrease regularly from 1.926 (for the pure compound) until the value of 1.837 (bulk V-6 material) depending on the vanadium addition level. The other values between 1.917 and 1.876 are calculated for the other materials. In this regard, it would be more precise to confirm that the formations of elastic (reversible) and plastic (irreversible) deformations emerge together in the Bi-2223 superconducting crystal structure but in the decrement trend. The reduction of Meyer number with the dopant level stems from the increased crystal structural problems, crack-producing omnipresent flaws, disorders, distortions, structural defects, porosity, voids, misorientations, lattice strains, cracks, grain boundary couplings and strength quality of connection between the grains in the Bi-2223 crystal structure.

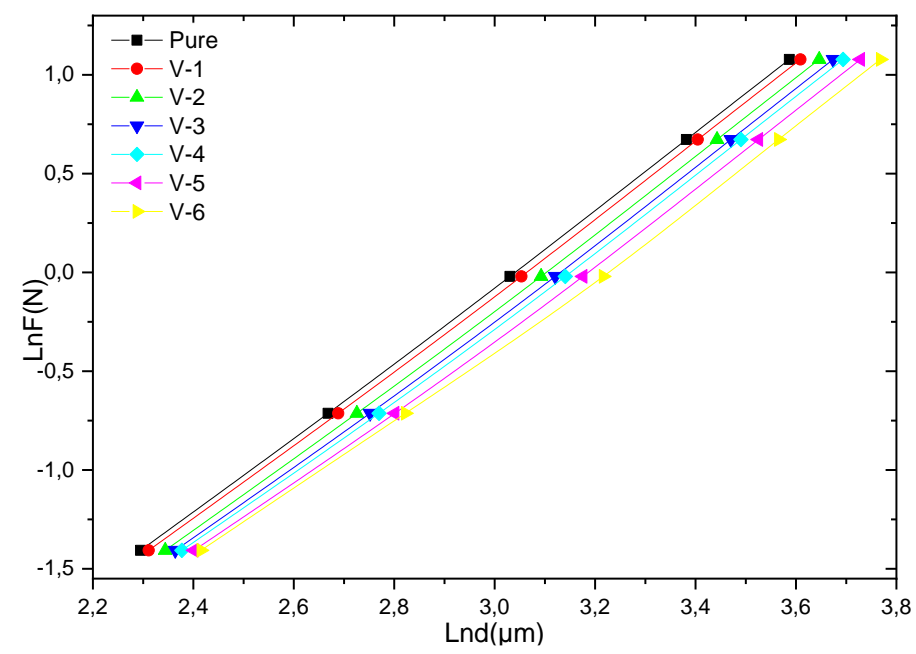

Figure 1. Variation of external test loads $\ln F$ versus diagonal tracks lnd for every material studied in this work. 
Table 2. Extrapolated parameters inferred from various theoretical models for vanadium added Bi-2223 superconducting materials $(0 \leq \mathrm{x} \leq 0.30)$.

\begin{tabular}{|c|c|c|c|c|c|c|c|}
\hline \multirow[b]{2}{*}{ Samples } & \multicolumn{2}{|c|}{ Meyer's Law } & \multicolumn{3}{|c|}{ MPSR Model } & \multicolumn{2}{|c|}{ HK Model } \\
\hline & $\begin{array}{l}\text { AMEYER X10 } \\
\left(\mathrm{N} / \mu \mathrm{m}^{2}\right)\end{array}$ & $\mathbf{n}$ & $\mathrm{W} \times 10^{-2}(\mathrm{~N})$ & $\begin{array}{c}\text { A0MPSR } \\
\mathbf{x 1 0 ^ { - 4 }} \\
(\mathrm{N} / \mu \mathrm{m})\end{array}$ & $\begin{array}{c}\operatorname{A}_{1 \mathrm{PSR}} \mathbf{x}^{-4} 0^{-4} \\
\left(\mathbf{N} / \mu \mathbf{m}^{2}\right)\end{array}$ & $\mathrm{W} \times 10^{-3}(\mathrm{~N})$ & $\begin{array}{c}\mathbf{A}_{3 \mathrm{HK}} \times 10^{-4} \\
\left(\mathrm{~N} / \mu \mathbf{m}^{2}\right)\end{array}$ \\
\hline Pure & -5.841 & 1.92 & 2.823 & -3.89 & 22.41 & 24.42 & 22.39 \\
\hline$V-1$ & -5.855 & $\begin{array}{c}1.91 \\
7\end{array}$ & 3.98 & -13.90 & 21.62 & 25.68 & 21.48 \\
\hline$V-2$ & -5.906 & $\begin{array}{c}1.91 \\
1\end{array}$ & 5.326 & -26.61 & 20.30 & 25.96 & 19.87 \\
\hline$V-3$ & -5.923 & $\begin{array}{c}1.90 \\
0\end{array}$ & 6.160 & -31.92 & 19.34 & 27.72 & 18.74 \\
\hline$V-4$ & -5.929 & $\begin{array}{c}1.89 \\
1 \\
\end{array}$ & 6.903 & -36.42 & 18.78 & 29.66 & 18.01 \\
\hline$V-5$ & -5.944 & $\begin{array}{c}1.87 \\
6\end{array}$ & 8.056 & -42.90 & 17.57 & 32.76 & 16.76 \\
\hline$V-5$ & -5.877 & $\begin{array}{c}1.83 \\
7\end{array}$ & 10.796 & -55.81 & 16.46 & 44.03 & 15.43 \\
\hline
\end{tabular}

\subsection{Role of Vanadium Addition on Original Microhardness Performance Parameters with Modified Proportional Sample Resistance Model}

After the proportional sample resistance model proposed by Li and Bradt to search the true mechanical performances of a superconducting material [24], the model needs to be modified by a new term of minimum applied test load leading to the impression track on the material (abbreviated as $W_{M P S R}$ parameter in the model calculation). Moreover, the modified proportional sample resistance (MPSR) model allows the scientists to search whether the polycrystalline compound studied exhibits the typical $I S E$ feature or not. The calculation of model can be summarized as below:

$$
F=W_{M P S R}+A_{0 M P S R} d+A_{1 M P S R} d^{2}
$$

in the relation given, the $A_{O M P S R}$ and $A_{\text {IMPSR }}$ parameters ascribe to the dissipation energies founded on the plastic deformations due to the presence of residual flaws, porosities, voids and cracks on the sample surfaces in the unit volume. One can encounter the variations of external indentation test load against the impression lengths are depicted in Figure 2 (linear differentiations of $F$ against $d$ curves). The curve slopes and crossing points on the y-axis are deduced according to the extrapolation method and all the values ( $W_{M P S R}, A_{O M P S R}$ and $A_{I M P S R}$ ) obtained are numerically listed in Table 2 . It is obvious from the table that every calculation for the $A_{\text {IMPSR }}$ parameters is found to be in a range of $22.41 \times 10^{-4}$ $\mathrm{N} / \mu \mathrm{m}$ (for the pure sample)-16.46 $\times 10^{-4} \mathrm{~N} / \mu \mathrm{m}$ (for the bulk V-6 sample). Here, according to the values of $A_{\text {IMPSR }}$ parameters the two important findings are obtained: (I) all the materials exhibit the ISE behavior due to the positive $A_{I M P S R}$ values and (II) the ISE feature tends to decrease systematically with the increment in the vanadium addition level up to the value of $x=0.30$. That is, the latter finding points out that the existence of vanadium dopant in the Bi-2223 crystal structure leads to degrade considerably the mechanical strength, stability, stiffness, critical stress, toughness, flexural strengths and mechanical durability. 


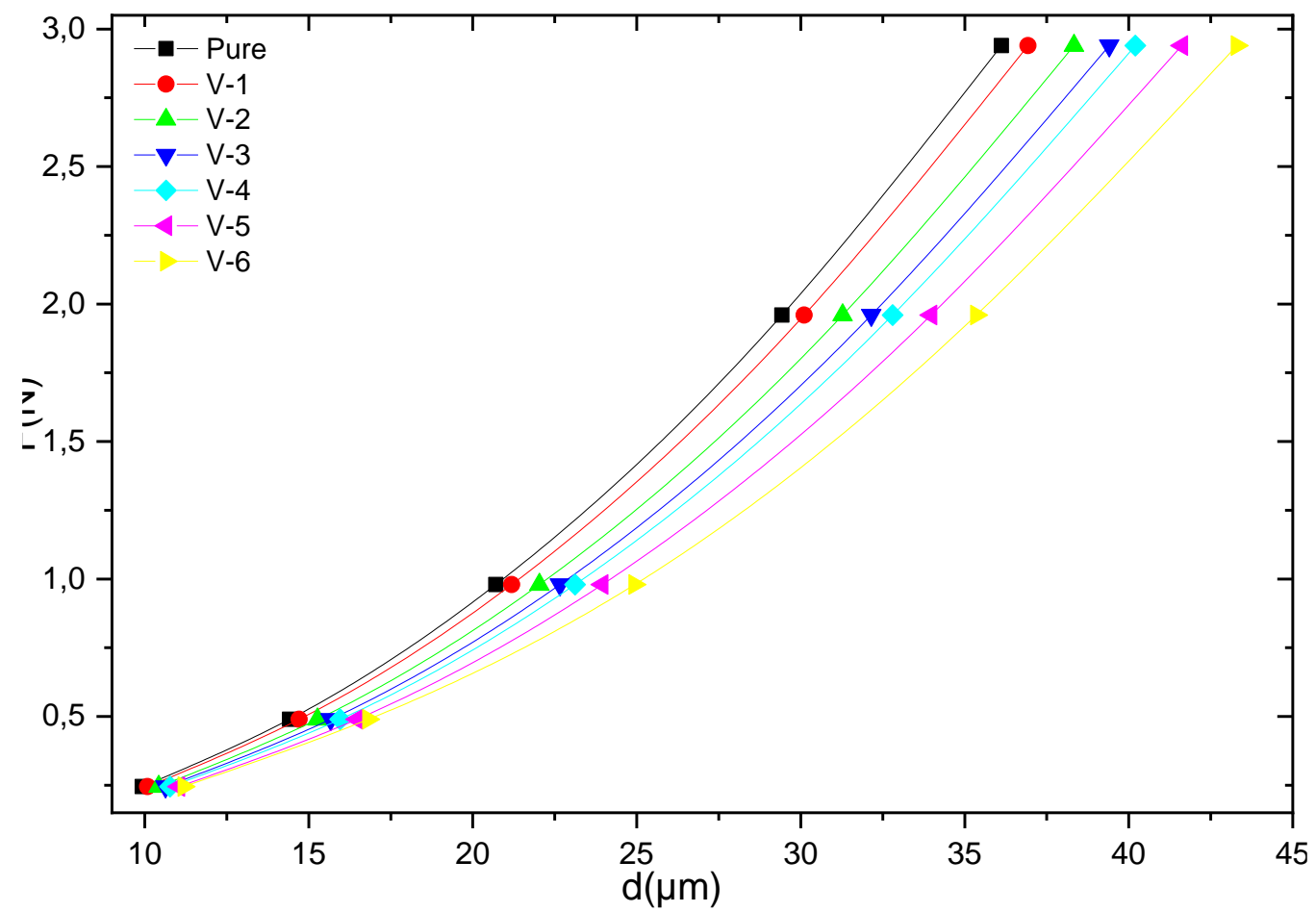

Figure 2. Linear plots of applied indentation test load $F$ versus indentation diagonal length $d$ for pure and vanadium added $\mathrm{Bi}-2223$ superconducting ceramic compounds

\subsection{Examination of True Microhardness Parameters for Vanadium Added Bi-2223 Materials with Respect to Hays-Kendall Approach}

Hays-Kendall $(H K)$ approach is another probable model to examine the critical changes in the loadindependent mechanical performances and characterization of pure and vanadium added Bi-2223 superconducting materials produced in this work. In the approach, it is mentioned that there is a critic indentation test load (abbreviated as $W$ ) to start the plastic deformation in the crystal structure for every material [25]. In other words, an applied load higher than the critical value leads an indenter to penetrate deeply into the bulk compounds. Thus, the $H K$ model describes an effective load ( $\left.F_{\text {eff }}=F-W\right)$ to find the differentiation in the impression diagonal lengths over the applied indentation test loads as given below:

$$
F-W=A_{3 H K} d^{2}
$$

where the value of $A_{3 H K}$ parameter is directly related to the microhardness parameter when the abbreviation of $W$ demonstrates the applied indentation test load resulting in the beginning of the plastic deformation in the crystal structure. One can see the linear relation graphs of applied load as a function of the square of impression lengths as shown in Figure 3 (linear variations of $F$ against $d^{2}$ curves). One can see all the extractions in Table 2. It is apparent from the table that all the calculations for the $A_{3 H K}$ parameters are noted to be in a range from the value of $22.39 \times 10^{-4} \mathrm{~N} / \mu \mathrm{m}^{2}$ (for the pure sample) to $15.43 \times 10^{-4} \mathrm{~N} / \mu \mathrm{m}^{2}$ (for the bulk V-6 compound). This is in correspondence to the fact that the pure and vanadium added $\mathrm{Bi}-2223$ superconducting ceramic materials exhibit the standard ISE behavior due to the positive $A_{3 H K}$ constants within the decrement trend. Namely, the decrement in the parameters with the dopant shows the regression in the mechanical strength, stability, stiffness, critical stress, toughness, flexural strengths and mechanical durability as a consequence of the increased crystal structural problems in the Bi-2223 crystal structure. 
We also determine the best model to examine the variations in the load-independent mechanical performances of the pure and vanadium added superconducting ceramic compounds by using the following relations.

$$
\begin{gathered}
H_{M P S R}=1854.4 A_{1 M P S R} \\
H_{H K}=1854.4 A_{3 H K}
\end{gathered}
$$

One can encounter all the computation values in Table 3. It is visible from the table that the findings of $H K$ approach are found to be much closer to the load-independent microhardness parameters as compared to those of the MPSR model. In this respect, the former model exhibits the strongest approach to determine the original microhardness parameters for the pure and vanadium added ceramic compounds. Regardless, the MPSR approach can serve as the suitable descriptor for the description of the differentiation in the original mechanical performances of the Bi-2223 superconducting materials.

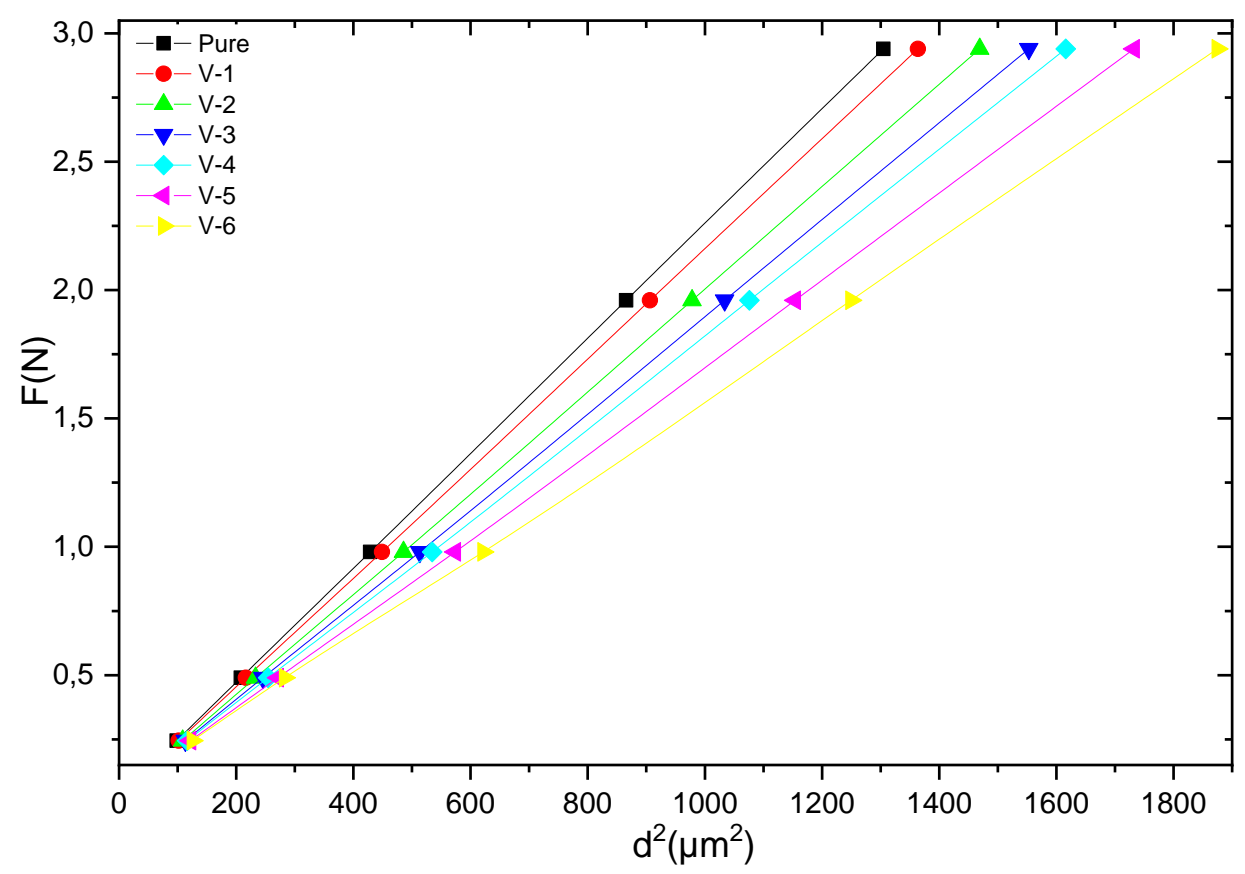

Figure 3. Linear plots of external indentation loads $\mathrm{F}$ over indentation lengths $d^{2}$ for all the materials.

Table 3. Comparisons of load-independent microhardness parameters.

\begin{tabular}{cccc}
\hline Samples & $\boldsymbol{H}_{\text {MPSR }}(\mathbf{G P a})$ & $\boldsymbol{H}_{\text {HK }}(\mathbf{G P a})$ & $\boldsymbol{H v}(\mathbf{G P a})$ \\
\hline Pure & 4.156 & 4.152 & $4.1787-4.1982$ \\
\hline $\mathrm{V}-1$ & 4.009 & 3.983 & $3.9983-4.0112$ \\
\hline $\mathrm{V}-2$ & 3.764 & 3.685 & $3.7107-3.7159$ \\
\hline $\mathrm{V}-3$ & 3.586 & 3.475 & $3.5108-3.5156$ \\
\hline $\mathrm{V}-4$ & 3.483 & 3.340 & $3.3741-3.3782$ \\
\hline $\mathrm{V}-5$ & 3.258 & 3.108 & $3.1471-3.1494$ \\
\hline $\mathrm{V}-6$ & 3.052 & 2.861 & $2.9080-2.9084$ \\
\hline
\end{tabular}




\section{CONCLUSION}

In the present work, the critical variation in the original mechanical performances of pure and vanadium added $\mathrm{Bi}-2223$ superconducting ceramic compounds produced within the molar ratios intervals $0 \leq x \leq 0.30$ by the available theoretical approaches such as Meyer's law, modified proportional sample resistance model and Hays-Kendall models founded on the Vickers hardness experimental results obtained from the different external indentation loads $(0.245 \mathrm{~N}-2.940)$ for the first time. It is observed that all the superconducting materials show the typical ISE feature but in the reduction trend as the vanadium addition level increases. Similarly, all the models studied in this work declare that the elastic (reversible) and plastic (irreversible) deformations appear together in the Bi-2223 superconducting crystal structure but in the decrement trend due to the increased crystal structural problems. On this basis, the presence of vanadium impurtiy in the Bi-2223 crystal structure leads to degrade considerably the mechanical strength, stability, stiffness, critical stress, toughness, flexural strengths and mechanical durability. As for the comparison between the findings of models, the $H K$ approach is noted to exhibit much closer results to the load-independent microhardness parameters as compared to those of the MPSR approach.

\section{ACKNOWLEDGEMENTS}

This work was supported by Bolu Abant Izzet Baysal University, Department of Chemistry and Department of Mechanical Engineering.

\section{REFERENCES}

[1] Wang FE. IV-Superconductivity, Bonding Theory for Metals and Alloys, 2005; 65-108.

[2] Ulgen AT, Belenli I. Sintering time dependence of iron diffusion in $\mathrm{MgB}_{2}$ and its effect on superconducting properties, AIP Conference Proceedings, 2017; 1815: 040008.

[3] Coombs TA, A finite element model of magnetization of superconducting bulks using a solidstate flux pump, IEEE T. Appl. Supercond., 2011; 21: 3581-3586.

[4] Runde M, Application of high- $T_{c}$ superconductors in aluminum electrolysis plants, IEEE T. Appl. Supercond., 1995; 5: 813-816.

[5] Ulgen AT, Belenli I. The Effect of Fe Diffusion on some physical and superconducting properties of MgB2, J. Supercond. Nov. Magn., 2017; 30: 1089-1095.

[6] Xu HH, Cheng L, Yan SB, Yu DJ, Guo LS, Yao X. Recycling failed bulk YBCO superconductors using the $\mathrm{NdBCO} / \mathrm{YBCO} / \mathrm{MgO}$ film-seeded top-seeded melt growth method, $\mathrm{J}$. Appl. Phys., 2012; 111: 103910.

[7] Guner SB, Zalaoglu Y, Turgay T, Ozyurt O, Ulgen AT, Dogruer M, Yildirim G. A detailed research for determination of $\mathrm{Bi} / \mathrm{Ga}$ partial substitution effect in $\mathrm{Bi}-2212$ superconducting matrix on crucial characteristic features, J. Alloy. Compd., 2019; 722: 388-398.

[8] Nagaya S, Hirano N, Naruse M, Watanabe T, Tamada T. Development of a high-efficiency conduction cooling technology for SMES coils, IEEE T. Appl. Supercond., 2013; 23: 56028045602807. 
[9] Choi KY, Jo IS, Han SC, Han YH, Sung TH, Jung MH, Park GS, Lee SI. High and uniform critical current density for large-size YBa2Cu3O7-y single crystals, Curr. Appl. Phys., 2011; 11: $1020-1023$.

[10] Ulgen AT, Karaboga F, Karakaya M, Podila R, ARao AM, Belenli I. Improved transport properties of $\mathrm{MgB} 2$ superconducting round wires via minute addition of gold nanoparticles, Ceram. Int., 2019; 45: 1031-1036.

[11] Karaboga F, Ulgen AT, Yetis H, Akdogan M, Pakdil M, Belenli I. Mechanical properties and uniformity of Fe-MgB $\mathrm{MB}_{2}$ wires upon various wire drawing steps, Mat. Sci. Eng. A-Struct., 2018; 721: 89-95.

[12] Buckel W, Kleiner R. Superconductivity: Fundamentals and Applications, $2^{\text {nd }}$ ed., Wiley-VCH Verlag, Weinheim, 2004.

[13] Hasegawa T, Koizumi T, Hikichi Y, Nakatsu T, Scanlan R, Hirano N, Nagaya S. IEEE Trans. Appl. Sup., 2012; 12: 1136.

[14] Miao H, Marken KR, Meinesz M, Czabaj B, Hong S. IEEE Trans. Appl. Sup., 2005; 15: 2554.

[15] Tarascon J, McKinnon W, Barboux P, Hwang D, Bagley B, Greene L, Hull G, Lepage Y, Stoffel N, Giroud M. Phys. Rev. B., 1988; 38: 8885-8892.

[16] Pickett WE. Electronic-structure of the high-temperature oxide superconductors, Rev. Mod. Phys., 1989; 61: 433-512.

[17] Biju A, Aloysius RP, Syamaprasad U. Enhanced critical current density in Gd-added (Bi, Pb)2212 bulk superconductor, Supercond. Sci. Technol., 2005; 18: 1454-1459.

[18] Egi T, Wen JG, Kuroda K, Unoki H, Koshizuka N. High-current density of $\mathrm{Nd}(\mathrm{Ba}, \mathrm{Nd})_{2} \mathrm{Cu}_{3} \mathrm{O}_{7-\mathrm{X}}$ single-crystal, Appl. Phys. Lett., 1995; 67: 2406-2408.

[19] Zhou L, Zhang P, Ji P, Wang K, Wu X. The properties of YBCO superconductors prepared by a new approach-the powder melting process, Supercond. Sci. Technol., 1990; 3: 490-492.

[20] Ling HC, Yan MF. Microhardness measurements on dopant modified superconducting YBa2Cu3O7 ceramics J. Appl. Phys., 1988; 64: 1307.

[21] Kolemen U, Uzun O, Yilmazlar M, Guclu N, Yanmaz E. Hardness and microstructural analysis of $\mathrm{Bi1} .6 \mathrm{~Pb} 0.4 \mathrm{Sr}_{2} \mathrm{Ca}_{2}-\mathrm{xSmxCu} 3 \mathrm{Oy}$ polycrystalline superconductors. J. Alloy. Compd.,2006; 415: 300-306.

[22] Mohammed NH, Abou-Aly AI, Ibrahim IH, Awad R, Rekaby M. Mechanical properties of (Cu0. 5T10. 5)-1223 added by nano-SnO 2 . J. Alloy. Compd., 2009; 486: 733-737.

[23] Dogruer M, Yildirim G, Ozturk O, Belenli I, Terzioglu C. Variation of Mechanical Properties of Cr Doped Bi-2212 Superconductors. J. Supercond. Nov. Magn., 2013; 26: 2949.

[24] Li H, Bradt RC. The microhardness indentation load/size effect in rutile and cassiterite single crystals. J. Mater. Sci., 1993; 28: 917-926.

[25] Hays C, Kendall EG. An analysis of knoop hardness., Metallography 1973; 6: 275-282. 